\title{
ENTRE POLÍTICAS CURRICULARES E POLÍTICAS EDUCACIONAIS SOBRE TECNOLOGIAS: um estado do conhecimento
}

\author{
Hugo Souza Garcia Ramos \\ Universidade Federal do Espírito Santo - UFES \\ Geide Rosa Coelho \\ Universidade Federal do Espírito Santo - UFES
}

\begin{abstract}
Resumo
Este artigo apresenta um estado do conhecimento sobre os seguintes campos acadêmicos: Políticas Curriculares, Políticas Educacionais e Tecnologias. Para composição do corpus analítico buscamos, no período de 1990-2019, artigos publicados nos eventos da Associação Nacional de Pós-Graduação e Pesquisa em Educação (ANPED), e as dissertações e teses disponibilizadas na Biblioteca Digital Brasileira de Teses e Dissertações (BDTD). O estudo foi orientado pela abordagem teóricometodológica da análise do discurso de Michel Foucault (1971; 1979; 1986), em que discutimos o modo como o jogo enunciativo dos pesquisadores configuram práticas discursivas nas quais ocorrem disputas e negociações permanentes de saberes e verdades, que formam as redes de conhecimento sobre o campo. Entre os principais resultados, está a grande ênfase dos pesquisadores em analisar e avaliar o processo de implementação das políticas educacionais em diferentes municípios do Brasil e, consequentemente, nos múltiplos cotidianos escolares. Além disso, identificamos uma lacuna na literatura a respeito de pesquisas sobre tecnologias nas políticas curriculares.
\end{abstract}

Palavras-chave: Políticas Curriculares, Políticas Educacionais; Tecnologias; Análise do discurso; Estado do conhecimento.

\begin{abstract}
This article presents the state of knowledge about the following academic fields: Educational Policies, Curriculum Policies and Technologies. For the composition of the analytical corpus we search, in the period 1990-2019, published in article format in the events of the National Association of Graduate Studies and Research in Education (ANPED), and the dissertations and theses made available at the Brazilian Digital Library of Theses and Dissertations (BDTD). The study was guided by the theoretical-methodological approach of the analysis of the discourse of Michel Foucault (1971; 1979; 1986), in which we demonstrate the way the enunciative game of the researchers configure discursive practices in which disputes and permanent negotiations of knowledge and truths occur, that form networks of knowledge about the field. Among the main results, there is the great emphasis of the researchers in analyzing and evaluating the process of implementing educational policies in different counties in Brazil and, consequently, in the multiple school routines. In addition, we identified a gap in the literature regarding research on technologies in curriculum policies.
\end{abstract}

Key-words: Curriculum Policies; Educational Policies; Technologies; Analysis of the discourse; State of knowledge. 


\section{Introdução}

Nos anos de 1980, iniciou-se o processo de incorporação das tecnologias na educação, impulsionado, principalmente, por meio de políticas educacionais. No ano de 1983, surgiu o Projeto Educom, sob a coordenação do Ministério da Educação, voltado para a pesquisa e a formação de recursos humanos. "Os estudos desenvolvidos no projeto buscavam estimular a construção e a consolidação de uma cultura nacional de informática educativa, centrada na especificidade da escola pública brasileira” (SOSSAI; GRIMM; LOUREIRO, 2016, p. 42).

Diante deste contexto, este artigo apresenta um estado do conhecimento no campo das políticas relativas às tecnologias, tanto as curriculares quanto educacionais. De acordo com Romanowski e Ens (2006), um estado do conhecimento tem por objetivo realizar levantamentos e sistematizações do que se conhece sobre um tema a partir de pesquisas realizadas em uma determinada área (ou campo teórico) e, salientam, que deve incluir pelo menos um setor de publicação. Nesse sentido, para composição do corpus analítico buscamos pesquisas, no período de 1990-2019, publicadas em formato de artigo nos eventos da Associação Nacional de Pós-Graduação e Pesquisa em Educação (ANPED), e as dissertações e teses disponibilizadas na Biblioteca Digital Brasileira de Teses e Dissertações (BDTD). Assim sendo, efetivamos um mapeamento que não se restringiu somente a identificar a produção. A finalidade foi realizar uma análise crítica com vistas a localizar tendências, lacunas, recorrências e disputas discursivas que vem sendo construídos sobre a temática no estado atual da ciência.

Nosso estudo foi orientado pela abordagem teórico-metodológica da análise do discurso de Michel Foucault (1971; 1979; 1986). Para tanto, é preciso compreender o discurso enquanto produção que se dá a partir da dimensão da prática social vinculado diretamente a "um conjunto de regras anônimas, históricas, sempre determinadas no tempo e no espaço, que definiram, em uma dada época e para uma determinada área social, econômica, geográfica ou lingüística, as condições de exercício da função enunciativa” (FOUCAULT, 1986, p. 136). Desse modo, tentaremos discutir como o jogo enunciativo dos pesquisadores configuram práticas discursivas nas quais ocorrem disputas e negociações permanentes de saberes e verdades que formam as redes de conhecimento sobre o que se investiga em Política Educacional, Políticas Curriculares e Tecnologias.

O entendimento da política como discurso, a partir deste referencial, implica assumir que uma verdade é produzida no discurso das políticas e que governa os sujeitos. Isso ocorre, já que o discurso nas políticas está diretamente relacionado às dinâmicas de poder e saber de uma época. Em outras palavras, refletem uma "vontade de verdade" que, provisória e contingencialmente, engendra um regime de verdade. Por outro lado, isto não interrompe o fluxo das diferenças que possibilitam reconstruir novas enunciações. É importante entender que "diferentes comunidades e sujeitos atuam nas políticas curriculares e produzem novos sentidos, principalmente, pela introdução de suas interpretações” (LOPES; MACEDO, p.237, 2011).

Por último, para analisar as diferentes concepções de tecnologia encontradas nas pesquisas, aproximamo-nos da perspectiva contemporânea da Filosofia da tecnologia, a partir 
do filósofo Andrew Feenberg (2003; 2015). Para o autor, podemos averiguar as concepções de tecnologia em quatro principais teorias: Instrumental, Determinista, Substancialista e Crítica. Além destas, trazemos as teorias pós-críticas que partem de uma concepção que as tecnologias são um vetor especial de um processo peculiar de subjetivação que tem modificado os modos de experimentação de si e do mundo (FONSECA; COSTA; KIRST, 2008). Com elas, tornou-se impossível pensar a tecnologia simplesmente por meio das fronteiras do instrumental, de valores sociais, ou ainda como lugar de poder.

Deste modo, o que está em jogo é pensar a tecnologia como multiplicidade, uma concepção que está sintonizada com a invenção e com uma região ontológica. As tecnologias como máquinas de produção e criação. Consideramos, assim, que a concepção pós-crítica nos permite percorrer um horizonte mais vasto e complexo para compreender a relação da tecnologia com os nossos modos de viver, pensar, comunicar e educar.

\section{Delineamento metodológico}

A realização de uma pesquisa do tipo estado do conhecimento (assim como os estados da arte) precisa seguir, de acordo com Romanowski (2002, p.15-16), os seguintes procedimentos:

- definição dos descritores para direcionar as buscas a serem realizadas;

- localização dos bancos de pesquisas, teses e dissertações, catálogos e acervos de bibliotecas, biblioteca eletrônica que possam proporcionar acesso a coleções de periódicos, assim como aos textos completos dos artigos;

- estabelecimento de critérios para a seleção do material que compõe o corpus do estado da arte;

- levantamento de teses e dissertações catalogadas;

- coleta do material de pesquisa, selecionado junto às bibliotecas de sistema COMUT ou disponibilizados eletronicamente;

- leitura das publicações com elaboração de síntese preliminar, considerando o tema, os objetivos, as problemáticas, metodologias, conclusões, e a relação entre o pesquisador e a área;

- organização do relatório do estudo compondo a sistematização das sínteses, identificando as tendências dos temas abordados e as relações indicadas nas teses e dissertações;

- análise e elaboração das conclusões preliminares.

Tendo em vista estas etapas, elaboramos para o desenvolvimento deste estudo, os nossos procedimentos metodológicos. Primeiro recorremos às pesquisas de mestrado e doutorado da Biblioteca Digital Brasileira de Teses e Dissertações (BDTD), que é mantida pelo Instituto Brasileiro de Informação em Ciência e Tecnologia (IBICT). Sua escolha se justifica pelo fato de conseguir integrar, em um único portal, os sistemas de informação de teses e dissertações existentes no Brasil. Analisamos também os artigos apresentados como trabalhos completos 
à Associação Nacional de Pós-Graduação e Pesquisa em Educação (ANPED). A busca foi efetivada por meio de todos os Grupos de Trabalho (GT) que possuem uma relação profícua com o campo proposto nesta pesquisa: Estado e Política Educacional (GT-5), Currículo (GT12) e Educação e Comunicação (GT-16). A escolha da ANPED se deu considerando ser um espaço em que se congrega o maior número de pesquisadores da área da educação no Brasil, além do nível de prestígio e autoridade que possui no meio acadêmico.

Após a definição do repositório dessas duas instâncias acadêmicas, fizemos a busca pela seguinte combinação de descritores: (Currículo OR Educação OR “Educação Básica”) AND ("Políticas Educacionais" OR "Políticas Públicas em Educação” OR "Políticas Curriculares”) AND (Tecnologias OR “Tecnologias da informação e da comunicação” OR “Tecnologias digitais” OR “Informática e Educação”).

As etapas dos procedimentos metodológicos estão registradas no quadro 1. A primeira fase consiste no levantamento de dissertações e teses na BDTD e dos trabalhos publicados no GT 05, GT 12 e GT 16 da ANPED, ambos no período entre 1990 e 2019¹. No caso da ANPED, a localização dos artigos demanda a investigação em cada reunião anual ${ }^{2}$, já que não é possível realizar uma busca com palavras-chave no site da Associação. Para a seleção dos trabalhos, foram observados os títulos e as palavras-chave ${ }^{3}$ utilizadas nos textos. $\mathrm{E}$ um dos critérios de inclusão foi que a pesquisa precisava estar relacionada com a Educação Básica e ter vinculação com alguma política educacional ou curricular.

$\mathrm{Na}$ segunda fase, realizamos uma pré-análise dos artigos, teses e dissertações selecionados na fase anterior por meio da leitura de todos os resumos. O critério de seleção dos trabalhos para compor o corpus da revisão foi a relação conjunta entre os campos de estudo investigados. Desse modo, não era do nosso interesse pesquisas que abordassem, por exemplo, a relação entre a juventude e as tecnologias. Essas publicações foram descartadas nessa etapa, por não se relacionarem com as temáticas que estamos investigando.

Na terceira e última fase, realizamos uma leitura completa do material selecionado para poder, assim, efetivar a análise. Nesse contexto, buscamos mapear a perspectiva epistemológica (por exemplo: positivismo, humanismo, marxismo, neomarxismo, estruturalismo, pós-estruturalismo, pluralismo, dentre outros), a política de tecnologia abordada (ou o programa, projeto, ação focado), o quantitativo de produções conforme a região geográfica do Brasil e, por fim, as nomenclaturas utilizadas para se referir às tecnologias. Ao final, apresentamos uma sistematização dos dados e as categorias de análise.

Quadro 1 - Procedimentos metodológicos para levantamento do corpus do estado do conhecimento.

\begin{tabular}{|c|l|l|}
\hline ETAPAS & \multicolumn{1}{|c|}{ MOVIMENTO } & \multicolumn{1}{c|}{ PROCEDIMENTOS } \\
\hline \multirow{4}{*}{$\mathbf{1}^{\text {a ETAPA }}$} & $\begin{array}{l}\text { Levantamento dos trabalhos publicados no GT } \\
\text { 05, GT 12 e GT 16 da ANPED no período entre } \\
\text { 1990 e 2019 e seleção dos que tratam de } \\
\text { políticas educacionais, currículo e tecnologias. }\end{array}$ & $\begin{array}{l}\text { Leitura do título e palavras- } \\
\text { chave. }\end{array}$ \\
\cline { 2 - 3 } & $\begin{array}{l}\text { Levantamento das dissertações e teses na } \\
\text { BDTD no período entre 1990 e 2019 e seleção }\end{array}$ & $\begin{array}{l}\text { Leitura do título e palavras- } \\
\text { chave. }\end{array}$ \\
\hline
\end{tabular}




\begin{tabular}{|c|l|l|}
\hline & $\begin{array}{l}\text { dos que tratam de políticas educacionais, } \\
\text { currículo e tecnologias. }\end{array}$ & \\
\hline \multirow{2}{*}{$\mathbf{2}^{\text {a }}$ ETAPA } & $\begin{array}{l}\text { Pré-análise dos artigos, teses e dissertações } \\
\text { selecionados para verificação da pertinência ao } \\
\text { objetivo proposto pelo nosso estudo. }\end{array}$ & $\begin{array}{l}\text { Leitura dos resumos dos artigos, } \\
\text { dissertações e teses. }\end{array}$ \\
\hline \multirow{3}{*}{$\mathbf{3}^{\text {a }}$ ETAPA } & $\begin{array}{l}\text { Análise dos artigos, teses e dissertações } \\
\text { selecionados e tabulação dos dados. } \\
\text { Definição das categorias analíticas (dimensão } \\
\text { qualitativa). }\end{array}$ & Leitura completa dos trabalhos. \\
\hline
\end{tabular}

Fonte: Elaborado pelos autores, 2020.

\section{0 corpus da pesquisa}

Em relação ao percurso do estudo, logo na primeira etapa do levantamento dos dados, encontramos um desafio devido à ausência e indisponibilidade dos arquivos. Na ANPED, somente está disponível, no formato digital, os artigos a partir da vigésima terceira reunião anual do ano 2000. E na BDTD, encontramos somente as teses e dissertações do período que sucede os anos 2000. Com isso, mesmo que tenhamos definido um recorte temporal mais amplo, os trabalhos que compõem os resultados são do período entre 2000 e 2019, podendo ser verificado na tabela 1 o percurso geral do levantamento:

Tabela 1 - Processo de levantamento dos trabalhos por etapa.

\begin{tabular}{c|c|ccccc}
\hline ETAPAS & PROCEDIMENTO & ARTIGOS & DISSERTAÇÕES & TESES & $\begin{array}{c}\text { TOTAL } \\
\text { GERAL }\end{array}$ \\
\hline $\mathbf{1}^{\text {a }}$ ETAPA & $\begin{array}{c}\text { Leitura do título e } \\
\text { palavras-chave. }\end{array}$ & 875 & 334 & 150 & 1359 \\
\hline $\mathbf{2}^{\text {a }}$ ETAPA & Leitura dos resumos & 57 & 27 & 18 & 102 \\
\hline $\mathbf{3}^{\text {a }}$ ETAPA & $\begin{array}{c}\text { Leitura completa dos } \\
\text { trabalhos. }\end{array}$ & 11 & 9 & 3 & 23 \\
\hline
\end{tabular}

Fonte: Elaborados pelos autores, 2020.

Na primeira etapa do estudo, encontramos um total de 1359 trabalhos $^{4}$ que estavam publicados nas duas instâncias acadêmicas. A partir disso, realizamos a leitura do título e das palavras-chave. Conseguimos, com esse filtro, realizar uma pré-seleção total de 57 artigos da ANPED e 45 pesquisas nas BDTD. Na segunda etapa, foram lidos os resumos na íntegra desse material pré-selecionado, dentre eles, foram elegidos 11 artigos, 9 dissertações e 3 teses. Portanto, após a leitura completa dos trabalhos, o corpus que compõe esta pesquisa conta com o total de 23 trabalhos.

Nesse primeiro momento, julgamos importante tecer breves considerações de cunho quantitativo acerca do conjunto de produções identificadas nos bancos de dados. Expomos as publicações ao longo dos anos; a relação do número de artigos publicados em cada GT da ANPED por ano; o quantitativo de produções conforme a região geográfica do Brasil; as 
perspectivas epistemológicas adotadas nos trabalhos; a política de tecnologia analisada; assim como destacamos as nomenclaturas utilizadas para se referir às tecnologias.

O gráfico da figura 1 tem o objetivo de apresentar a distribuição dos trabalhos por ano. Nele, é possível identificar e acompanhar a evolução anual, desde 2000 até 2019.

Figura 1 - Gráfico das publicações ao longo dos anos.

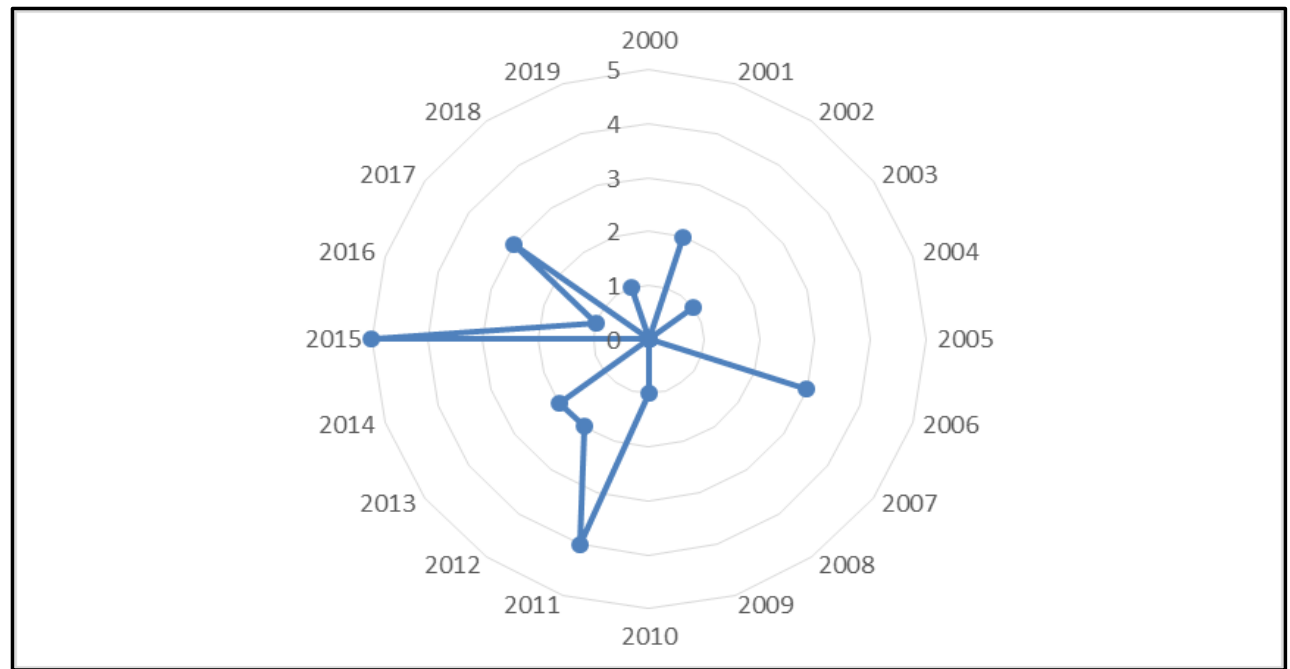

Fonte: Elaborado pelos autores, 2020.

A partir das informações referentes ao gráfico, percebe-se que no ano de 2001 identificamos duas publicações. Já em 2003 houve somente uma. Se observarmos o ano de 2006, foram publicados três trabalhos, e um fato a ser destacado é que todos analisaram o Programa Nacional de Informática Educativa (PROINFO). No período de 2009 até 2011 ocorreu um aumento significativo de produções, conforme demostrado no gráfico. Pode-se supor que o aumento expressivo no número total de trabalhos desse período se deve à nova atualização do PROINFO ${ }^{5}$ em 2007 e a implementação do Programa Um Computador por Aluno (PROUCA) em 2010.

Nos anos de 2012 e 2013, foram encontrados dois trabalhos em cada. Já em 2015 foi o ano com maior número de trabalhos, totalizando cinco publicações. Em 2016 houve uma queda, tendo somente uma publicação. Por último, no ano de 2019, ocorreu somente uma publicação.

Observamos uma tendência de declínio no número de trabalhos a partir de 2015. Com isso, perguntamos: quais são as possíveis causas? Será que os aspectos políticos, sociais e econômicos da época podem ter impactado? A diminuição na valorização da ciência e, consequentemente, no incentivo de investimentos de novas pesquisas refletem nesses dados?

Fica perceptível que no ano de 2000, assim como em 2002, 2004, 2005, 2007, 2008, 2014 e 2018 não foram localizadas nenhuma publicação. Esses dados demonstram que os estudos que relacionam os três campos acadêmicos, os quais estamos investigando, possuem uma oscilação de publicações ao longo dos anos. 
A finalidade da tabela 2 é apresentar a relação do número de artigos publicados, nas últimas duas décadas, em cada GT da ANPED.

Tabela 2 - Número de artigos publicados em três GTs da ANPED.

\begin{tabular}{|c|cc|cc|cc}
\hline & \multicolumn{2}{|c|}{ GT 05 } & \multicolumn{2}{|c|}{ GT 12 } & \multicolumn{2}{c|}{ GT 16 } \\
\hline Reunião & Total de & Trabalhos & Total de & Trabalhos & Total de & Trabalhos \\
Trabalhos & selecionados & Trabalhos & selecionados & Trabalhos & selecionados \\
\hline 2000 & 19 & 0 & 16 & 0 & 15 & 0 \\
\hline $24^{\text {a } 2001}$ & 19 & 1 & 17 & 0 & 12 & 1 \\
\hline $25^{\text {a } 2002}$ & 10 & 0 & 10 & 0 & 10 & 0 \\
\hline $26^{\text {a } 2003}$ & 20 & 0 & 13 & 0 & 20 & 1 \\
\hline $27^{\text {a } 2004}$ & 22 & 0 & 12 & 0 & 18 & 0 \\
\hline $28^{\text {a } 2005}$ & 15 & 0 & 18 & 0 & 28 & 0 \\
\hline $29^{\text {a } 2006}$ & 17 & 0 & 11 & 0 & 17 & 0 \\
\hline $30^{\text {a } 2007}$ & 24 & 0 & 15 & 0 & 20 & 0 \\
\hline $31^{\text {a } 2008}$ & 16 & 0 & 17 & 0 & 25 & 0 \\
\hline $32^{\text {a } 2009}$ & 12 & 0 & 17 & 0 & 22 & 0 \\
\hline $33^{\text {a } 2010}$ & 20 & 0 & 18 & 0 & 15 & 0 \\
\hline $34^{\text {a } 2011}$ & 22 & 0 & 29 & 1 & 22 & 2 \\
\hline $35^{\text {a } 2012}$ & 19 & 0 & 15 & 0 & 14 & 1 \\
\hline $36^{\text {a } 2013}$ & 17 & 0 & 18 & 0 & 20 & 2 \\
\hline $37^{\text {a } 2015}$ & 30 & 0 & 27 & 1 & 21 & 1 \\
\hline $38^{\text {a } 2017}$ & 23 & 0 & 20 & 0 & 18 & 0 \\
\hline Total & 305 & $\mathbf{1}$ & 273 & $\mathbf{2}$ & $\mathbf{2 9 7}$ & $\mathbf{8}$ \\
\hline
\end{tabular}

Fonte: Elaborado pelos autores, 2020.

A partir das informações referentes à tabela 2, observamos uma escassez de trabalhos que tratam de políticas educacionais, currículo e tecnologias. Embora haja um elevado número de publicações em cada GT, os que abordam a temática referida da nossa pesquisa, não são expressivos. Como é possível verificar, há uma ausência também de trabalhos no GT 12 (Currículo), já que em 19 anos encontramos somente dois artigos (FARIAS, 2015; VELLOSO, 2011). Nesse contexto, é válida a suposição de que existe uma lacuna de pesquisas que buscam problematizar a relação entre o currículo e as tecnologias. 
É digno de nota que o GT 5, cujo foco são as políticas educacionais, tenha uma única publicação (SIQUEIRA, 2001) ao longo de 16 reuniões. Vale destacar que na década de 1990 surgiu a implementação de várias políticas visando a inserção das tecnologias nas escolas, por outro lado, parece-nos que produziu poucos efeitos nas décadas seguintes nos estudos desse grupo da ANPED.

Constatamos que o maior número de trabalhos (CORREA E CASTRO, 2011; LINHARES; FERREIRA, 2012; PISCHETOLA, 2015; SANTOS, 2013; SOARES; VALENTINI, 2011; TOSTA; OLIVEIRA, 2001; VELLOSO, 2013; VIEIRA, 2003) se concentra no GT 16 (Educação e Comunicação). Para além dos trabalhos selecionados, foi possível verificar também que nesse GT temos o maior número de pesquisas dedicadas às tecnologias com suas variadas temáticas. Talvez, isso se deva ao fato de que estamos na era das tecnologias de informação e comunicação, conforme destaca Castells (2000), em que um novo paradigma tecnológico floresceu e difundiu-se no final do século XX. O autor compara esse paradigma com a proporção da revolução industrial do século XVIII e afirma que o cerne da transformação se referiu às tecnologias da informação, processamento e comunicação.

Diante disso, os trabalhos acabam se relacionando e se inserindo dentro do campo acadêmico "Educação e Comunicação" e os pesquisadores, nos parecerem, que acabam direcionando suas publicações para o GT 16. Considerando o recorte temporal que utilizamos para a realização deste estado do conhecimento, as dissertações e teses selecionadas se distribuem em cada ano da seguinte forma:

Tabela 3 - Distribuição em cada ano de dissertações e teses selecionadas no site da BDTD.

\begin{tabular}{|ccc|}
\hline Ano & Dissertações & Teses \\
\hline 2006 & 0 & 2 \\
\hline 2009 & 1 & 0 \\
\hline 2011 & 1 & 0 \\
\hline 2012 & 0 & 1 \\
\hline 2014 & 1 & 0 \\
\hline 2015 & 3 & 0 \\
\hline
\end{tabular}

Fonte: Elaborado pelos autores, 2020.

De modo geral, percebemos na tabela acima o predomínio de um número muito maior de produção de dissertações (75\%) quando comparado ao número de teses (25\%). É notório que a partir do ano de 2014 ocorreu, com uma certa constância, de praticamente quase todo ano com publicações de dissertações.

No ano de 2006, tivemos a publicação de duas teses (FARIAS, 2006; LIMA, 2006). Já em 2009 e 2011, foram publicadas duas dissertações, uma em cada ano (MARTINS, 2009; 
OLIVEIRA, 2011). A tese de Sarian (2012) foi a responsável pela única publicação de 2012. Em 2014 foi localizada apenas uma dissertação (SILVA, 2014).

O ano de 2015 se destaca tendo a publicação de três pesquisas de mestrado (AMARAL, 2015; NÓBREGA, 2015; SANTOS, 2015). Já em 2017, foram publicadas duas dissertações (RICHITELI, 2017; SILVA, 2017). Por último, no ano de 2019, foi localizada somente uma dissertação (RODRIGUES, 2019).

Tabela 4 - As nomenclaturas utilizadas para se referir às tecnologias.

\begin{tabular}{c|l}
\hline \multicolumn{1}{c}{ QUANTIDADE } & \multicolumn{1}{c}{ NOMENCLATURAS UTILIZADAS } \\
\hline 8 & Tecnologias de Informação e Comunicação (TIC) \\
\hline 4 & Novas Tecnologias de Informação e Comunicação \\
\hline 1 & Tecnologias Digitais de Informação e Comunicação \\
\hline 4 & Tecnologias Digitais \\
\hline 2 & Novas tecnologias \\
\hline 4 & Tecnologias Educacionais \\
\hline
\end{tabular}

Fonte: Elaborado pelos autores, 2020.

É perceptível, a partir da tabela 4, um claro predomínio pela nomenclatura Tecnologias de Informação e Comunicação (TIC), contabilizando sua utilização em oito pesquisas. Acrescentam-se, ainda, quatro pesquisas que introduziram o adjetivo "novas" para se referirem a elas e também uma pesquisa que destacou a dimensão digital dessas tecnologias. Também foram localizados quatro estudos que trabalharam com o termo "tecnologias digitais”. Outras duas pesquisas, as quais inferimos que realizaram uma nomeação de forma mais ampla, utilizaram "novas tecnologias”. No que diz respeito às tecnologias educacionais, dos 23 trabalhos selecionados, 4 utilizam essa denominação.

Com essa variedade de nomenclaturas que as pesquisas utilizam, acaba-se por engendrar uma interpretação de sentidos múltiplos do que se entende por tecnologia. Supomos que isso se relaciona também ao modo pelo qual as políticas se referem a elas. Não há padrão nem linearidade, muda-se a cada política. É fato que, ao longo do tempo, o poder de atualização e inovação que as tecnologias sofrem é algo exponencial. Consideramos que isso pode vir a refletir nesses resultados que encontramos referentes a heterogeneidade nas terminologias.

Quanto à distribuição geográfica da produção acadêmica, verifica-se que há maior concentração de publicações oriundas de pesquisadores das Universidades localizadas na Região Sudeste, que concentra praticamente metade (42\%) do total nacional: 
Figura 2- Origem geográfica das publicações.

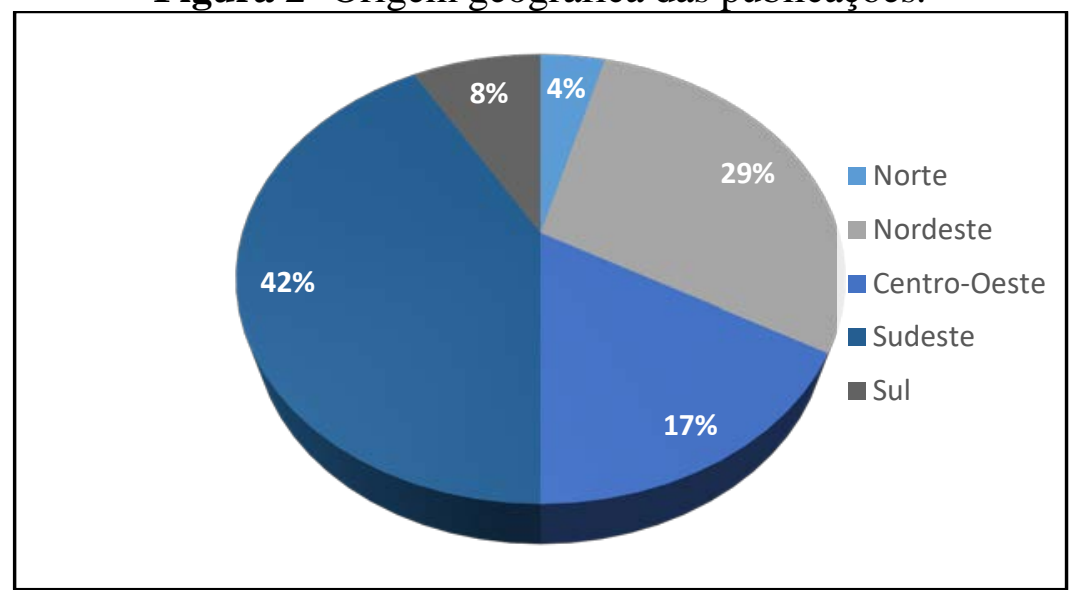

Fonte: Elaborado pelos autores, 2020.

Chama-nos atenção que 29\% (7) dos trabalhos se localizam na Região Nordeste, sendo que cinco deles tiveram como foco de pesquisa a implementação do PROINFO em diferentes estados dessa região.

No que se refere à perspectiva epistemológica, isto é, à teoria geral que o pesquisador assume para guiar sua investigação (TELLO, 2012), ressaltamos que encontramos grande dificuldade para sistematizar e descrever esses dados. Isso se deu pelo fato de os pesquisadores não deixarem clara a perspectiva adotada. Diante dessa constatação, decidimos seguir somente as declarações explícitas no texto. Optamos por não realizar classificações, tendo em vista os autores citados e as conceitualizações adotadas. Dessa forma, esperamos evidenciar uma questão que emergiu ao longo do processo de análise dessas produções e que, a nosso ver, é de extrema importância. O pesquisador deveria assumir sua posição epistemológica em uma determinada área de estudo e pesquisa que está sendo realizada.

Tabela 5 - Perspectivas epistemológicas assumidas nas pesquisas.

\begin{tabular}{|c|c|}
\hline QUANTIDADE & PERSPECTIVA EPISTEMOLÓGICA \\
\hline 4 & Teoria Crítica \\
\hline 2 & Abordagem do Ciclo de Política \\
\hline 1 & Teoria Pós-Crítica \\
\hline 1 & Sócio-Histórica \\
\hline 15 & Não identificada/declarada \\
\hline
\end{tabular}

Fonte: Elaborado pelos autores, 2020.

A partir dos dados da tabela 5, observa-se a predominância de pesquisas que seguiram a perspectiva da Teoria Crítica (FARIAS, 2006; OLIVEIRA, 2011; SANTOS, 2015; 
PISCHETOLA, 2015). Localizamos duas pesquisas que adotaram a Abordagem do Ciclo de Política (CORREA E CASTRO, 2011; NÓBREGA, 2015). Houve também uma pesquisa (VIEIRA, 2003) de base teórica Sócio-Histórica e uma (FARIAS, 2015) da Teoria PósCrítica. É importante frisar que na maior parte das pesquisas não conseguimos localizar a perspectiva epistemológica, chegando a mais de 50\% das produções acadêmicas do recorte temporal deste estudo.

No que diz respeito a qual política educacional ou curricular analisada pelos pesquisadores, observamos que algumas são tratadas com certa equivalência semântica com o nome de programas e projetos dos governos, por exemplo, Programa Salto para o Futuro.

Tabela 6 - Políticas, Programas, Projetos adotados nas pesquisas.

\begin{tabular}{c|l}
\hline QUANTIDADE & \multicolumn{1}{c}{ POLÍTICAS, PROGRAMAS, PROJETOS } \\
\hline $\mathbf{8}$ & Programa Nacional de Informática na Educação - PROINFO \\
\hline $\mathbf{9}$ & Programa Um Computador por Aluno PROUCA \\
\hline $\mathbf{1}$ & Programa Salto para o Futuro \\
\hline $\mathbf{1}$ & Projeto EDUCOM - Informática na Educação \\
\hline $\mathbf{1}$ & Plano Nacional de Educação \\
\hline $\mathbf{1}$ & $\begin{array}{l}\text { Diretrizes Curriculares Nacionais } \\
\text { "Metas Educativas 2021 - Síntese”, “Políticas de TIC en los Sistemas Educativos } \\
\text { de America Latina" e “Alfabetização midiática e informacional: currículo para } \\
\text { formação de professores”6 }\end{array}$ \\
\hline $\mathbf{1}$ &
\end{tabular}

Fonte: Elaborado pelos autores, 2020.

Com os resultados da tabela 5, nota-se que a ênfase da análise de políticas se concentra no PROINFO e no PROUCA, juntos, representam 74\% dos trabalhos. Inferimos que isso se deva ao fato de que esses dois programas são as duas maiores políticas educacionais voltadas para inserção das tecnologias nas escolas públicas brasileiras.

Vale dizer que somente duas pesquisas realizaram uma análise do discurso sobre tecnologias nas políticas curriculares. Um fato que nos chama atenção, considerando que esse é um número muito baixo, o que acaba demonstrando novamente a lacuna de estudos que tratem da relação do currículo com as tecnologias e, mais especificamente, de que forma as políticas curriculares estão contribuindo para a sua inserção.

Na próxima seção, apresentaremos duas grandes categorias analíticas que foram construídas a partir dos trabalhos selecionados. No primeiro momento, organizaremos os trabalhos de pesquisa sobre o programa PROINFO e o PROUCA com seus diferentes desdobramentos e implementações em diferentes municípios do Brasil, tendo em vista que essas duas foram as políticas mais analisadas nas pesquisas. No segundo tópico das análises, traremos os estudos investigados sobre tecnologias nas políticas curriculares. 
Destacamos que nem todas as teses, dissertações e artigos, localizadas nos repositórios e selecionados para compor o corpus deste estudo, têm espaço na discussão dos dados por ora realizada. Os trabalhos não contemplados abordam o Programa Salto para o Futuro, o Plano Nacional de Educação e o Projeto EDUCOM.

\subsection{Políticas educacionais e políticas curriculares: uma análise sobre tecnologias}

Para realizar a análise dos trabalhos, perguntamos: De que forma as políticas educacionais e curriculares sobre tecnologias têm se concretizado nas pesquisas acadêmicas? Quais elementos têm sido analisados pela literatura em relação a essas políticas? Procuramos, assim, tentar localizar "o quê" estas produções abordam, explicitando aspectos específicos de cada uma, bem como suas semelhanças, além das principais considerações e contribuições para o campo.

\subsubsection{As políticas educacionais sobre tecnologias: o debate do PROINFO e do PROUCA}

Uma breve contextualização acerca desses dois programas antes de trazer a discussão dos dados. Foi a partir da década de 1990 que tivemos inciativas com objetivo da inserção de computadores nas escolas públicas brasileiras. De acordo com Silva (2014), primeiro buscouse equipar as escolas com laboratórios de informática por meio do PROINFO. Depois, com a evolução das tecnologias, vislumbrou-se novas possibilidade de usar os equipamentos, não precisando ser "divididos” por mais de um aluno. Entrou em vigor, assim, o Programa Um Computador por Aluno (PROUCA), equipando escolas com notebooks.

Iniciamos as análises com os trabalhos relacionados ao PROINFO. Tosta e Oliveira (2001) procuraram identificar de que modo as novas tecnologias de comunicação e informação refletem nas práticas docentes. A pesquisa se dividiu em três etapas. A primeira, de caráter documental, com vistas a compreender as diretrizes dos documentos do PROINFO. A segunda e terceira parte foram caracterizadas pesquisas de campo. Uma delas é uma investigação, conforme as autoras denominam, de caráter exploratório junto ao Curso de Capacitação em Informática Educativa ministrado pelo Núcleo de Tecnologia Educacional criados pelo programa junto a um grupo de professores. A outra fase buscou verificar se a introdução de computadores provocou mudanças no espaço escolar em relação à prática docente e nas relações de ensino-aprendizagem.

Entre as principais considerações das autoras, está a de que o PROINFO teve a pretensão de preparar profissionais de ensino para implementar novos processos educacionais. $\mathrm{O}$ que se buscava, segundo as pesquisadoras, era superar as relações de ensino e aprendizagem de transmissão de informação para um paradigma de interação e coprodução do conhecimento. Isso seria possível a partir da inserção das tecnologias de comunicação e de informação no ambiente escolar. Observamos, aqui, a presença de uma tendência instrumentalista da tecnologia (FEENBERG, 2003; 2015), por meio da qual seu uso como ferramenta 
possibilitaria a ocorrência de outras formas de ensino e aprendizagem, como o modelo comunicacional interativo e dialógico defendido por Tosta e Oliveira (2001).

As autoras constataram com a pesquisa que não

[...] houve mudanças substantivas na organização e na pedagogia das escolas, assim como seus processos de ensino-aprendizagem se tornaram mais interativos e abertos. Seus tempos e espaços permanecem como que inalterados e a tecnologia se apresenta como um tipo de "anexo" onde professores e alunos pouco freqüentam e, quando o fazem, é como se estendessem o espaço da sala de aula para a sala de informática, sem as necessárias mediações de um projeto pedagógico que favorecesse o entendimento de uma outra lógica e de diferentes linguagens das quais essa tecnologia é portadora e que incidem na educação e, de resto, em toda a sociedade (TOSTA; OLIVEIRA, 2001, p. 15).

Nessa mesma direção, o trabalho de Correa e Castro (2011) aponta o laboratório de informática como um "corpo estranho" na escola, que fica dissociado do cotidiano letivo. Isso acontece, de acordo com a autora, pelo fato de que a inserção das TIC não ocorreu por demanda da educação.

As autoras compreendem que, antes mesmo que houvesse um espaço/tempo para acontecer, os computadores já se encontravam nas escolas para "formar recursos humanos para um potencial mercado de informática ou para inserir os indivíduos como operadores/consumidores na sociedade da informação”(CORREA E CASTRO, 2011, p. 9). Fica evidente que as tecnologias, muitas vezes, são reduzidas a uma dimensão utilitarista e, nesse caso, para formar capital humano para atender às demandas do mercado.

Correa e Castro (2011) analisaram a leitura do discurso do PROINFO na rede pública estadual de ensino do Rio de Janeiro a partir de quatro entrevistas com gestoras da Secretaria de Estado de Educação do Rio de Janeiro que estavam relacionadas com a implementação do programa. Encontraram, a partir da pesquisa, dois desafios que precisam ser considerados e superados sobre esse programa.

O primeiro apontado é a necessidade de superar um certo paralelismo, ou seja, quando as políticas de tecnologias educacionais são implementadas nas escolas e colocadas de forma paralela ao contexto da realidade cotidiana da instituição. Para as autoras essa superação é alcançada quando as políticas são tratadas de forma integrada ao contexto das escolas e no contexto mais amplo da educação. $\mathrm{O}$ segundo desafio identificado é a necessidade de reconstruir um outro modo de operar as políticas, que não seja de forma centralista e vertical. Ainda sugere criar espaços de participação e debates com os agentes envolvidos, de modo que eles possam colocar suas reflexões e sejam ouvidos.

O artigo de Vieira (2003) também verificou que os órgãos oficiais do programa não escutam as vozes do seu "auditório social" e que, assim, acabammascarando uma realidade. Os sujeitos entrevistados, de acordo com a autora, encontraram no contexto da entrevista um lugar para serem ouvidos e puderam denunciar alguns problemas enfrentados. 
[...] denunciam o desenvolvimento de uma política pública educacional proposta pelo governo e que só funciona no papel, pois ao se concretizar na prática esbarra numa série de problemas: falta de recursos financeiros para manutenção dos equipamentos, falta de verba para aquisição de material específico para o uso dos computadores, incompatibilidade da estrutura da escola com a nova estrutura exigida pelo programa, entre outros (VIEIRA, 2003, p. 9).

Essa pesquisa teve como objetivo compreender os diferentes discursos presentes no processo de implantação do PROINFO na cidade de Juiz de Fora. Segundo a pesquisadora, o discurso desse programa traz as novas tecnologias como possibilitadoras de produtividade, eficiência e desenvolvimento da sociedade e do país. Ainda aponta que há implicitamente um discurso de orientação neoliberal que perpassa o documento. Podemos verificar, a partir das contribuições da análise desse trabalho, a presença de uma possível concepção determinista da tecnologia (FEENBERG, 2003; 2015) no discurso da política do PROINFO, uma vez que considera a possibilidade de as tecnologias moldarem a sociedade de acordo com ideais de eficiência, produtividade e progresso.

Em outra busca, a tese de Farias (2006) tratou de apreender a racionalidade das novas tecnologias na educação brasileira tendo o PROINFO como objeto de análise. O estudo foi ancorado na teoria social crítica de Habermas e na análise do discurso como metodologia. Além da análise dos documentos, foram realizadas entrevistas em escolas tanto com educadores, quanto com educandos.

De acordo com a autora, as políticas educacionais sobre tecnologia, nesse caso o PROINFO, introduzem o discurso tecnológico da modernidade. Ela explicita melhor, afirmando que esse discurso foi caracterizado tendo a tecnologia como propulsora do crescimento econômico e que o "uso de NTCI é entendido como meio necessário para diminuir as desigualdades sociais, reduzindo pobreza e analfabetismo [...]” possibilitando "a melhoria do processo aprendizagem e favorecendo a democratização da informação” (FARIAS, 2006, p. 271).

Os dados decorrentes desse estudo evidenciaram dois tipos de racionalidades com a institucionalização do programa: a primeira, de caráter instrumental, que foi, de acordo com a pesquisadora, representada pelo discurso da modernidade, sendo fortemente marcada pelas seguintes palavras “atualização, eficácia, mercado de trabalho, rápido acesso à informação e aprendizagem veloz” (FARIAS, 2006, p. 275); a segunda, de caráter comunicativa, teve como palavras-chave "autonomia de aprendizagem, diálogo, criatividade, crítica e reconhecimento dos limites da inclusão/exclusão dos processos de modernidade” (FARIAS, 2006, p. 275).

Já a dissertação de Oliveira (2011) tratou de avaliar os impactos do PROINFO nas condições de vida dos alunos das escolas públicas da cidade de Fortaleza a partir do objetivo de verificar a relação do programa com o processo de inclusão sociodigital. O estudo foi efetivado por meio de pesquisas bibliográfica, documental e estudo de caso.

A pesquisadora afirmou que o acesso aos computadores não trouxe mudanças substantivas na vida dos alunos. No entanto, ressalta a importância do programa em permitir 
que os alunos das escolas públicas tenham acesso a um computador. Um dado interessante que emergiu na pesquisa é que o uso do laboratório de informática não provocou mudanças no processo de ensino e aprendizagem, o que foi constatado também por Tosta e Oliveira (2001) e por Correa e Castro (2011). Os trabalhos desenvolvidos ainda estavam submetidos, de acordo com Oliveira (2011), ao formato tradicional. Esses dados explicitam que é necessário, para além da incorporação das tecnologias, ocorrer, também, uma transformação no currículo escolar em seu molde ainda analógico de produzir conhecimento.

Encontramos ainda duas dissertações que analisaram a eficácia do PROINFO em escolas de ensino fundamental dos anos finais. Rodrigues (2019) realizou sua pesquisa na cidade de Gurupi em Tocantins, já Martins (2009) teve como foco a cidade de Natal, no Rio Grande do Norte. Ambos os trabalhos sinalizam que os objetivos do programa não foram plenamente atingidos, destacando como uma das causas a falta de capacitação ${ }^{7}$ tanto de professores quanto de profissionais para os laboratórios de informática. Nossa compreensão diverge nesse aspecto porque a análise do "fracasso" da política não pode incidir apenas no papel do professor, tampouco condicionar unilateralmente a questão da formação docente como solucionador do problema. Ao contrário, é preciso explorar a complexa interação dos múltiplos elementos constitutivos da execução de uma política educacional, nesse caso, o PROINFO.

Quanto às pesquisas efetivadas em torno do PROUCA, a dissertação de Nóbrega (2015) investigou o Programa Aluno Conectado (PAC) que corresponde a uma versão, do estado de Pernambuco, desta política. O PAC, segundo a autora, consiste na distribuição de um tablet por aluno das segundas e terceiras séries do ensino médio da rede pública estadual daquele estado. A pesquisa teve como aporte teórico-metodológico o ciclo de políticas formulado por Sthephen Ball e privilegiou quatro dos cinco contextos propostos por essa abordagem de análise de políticas: o contexto das influências, o contexto da produção de texto, o contexto das práticas, o contexto dos resultados/efeitos.

Entre as principais considerações da autora, está que a trajetória de programas governamentais voltados para a inserção das tecnologias nas escolas foram progressivamente se reduzindo à distribuição de dispositivos tecnológicos para fins de estudo e ensino. Destarte, aponta que políticas de Pernambuco e do Brasil se inserem no âmbito das tecnologias de política. É a partir dos conceitos de gerencialismo, governamentalidade e governo que a pesquisadora compreende que há uma transferência para o usuário, neste caso os alunos da responsabilidade de capacitar-se e fazer usos das novas tecnologias.

Nesse sentido, para a autora, o aluno passa a ser o maior responsável por sua "inclusão digital”, pois aos docentes cabe a participação condicionada à disponibilização dos aparelhos. Ainda destaca que esse processo "é coerente com a emergência de uma noção de inclusão digital reduzida ao acesso às ferramentas, alimentadas por uma concepção de um regime de eficiência inerente aos instrumentos tecnológicos quando considerados neutros" (NÓBREGA, 2015, p.49). O trabalho de Oliveira (2011) também defende que a inclusão digital precisa ser compreendida para além do acesso a uma máquina, precisando ser visto 
sob os aspectos socioeconômicos (ter condições financeiras de acesso às novas tecnologias) e cognitivos (dotar o aluno de uma visão crítica e de capacidade independente de uso e apropriação dos novos meios digitais, transformar informação em conhecimento) (OLIVEIRA, 2011, p. 119).

A dissertação de Silva (2017) se insere dentro do contexto de avaliação de políticas públicas educacionais e testou o impacto do PROUCA no rendimento acadêmico de estudantes do ensino fundamental nas escolas públicas brasileiras por meio do Índice de Desenvolvimento da Educação Básica (IDEB). De acordo com a autora, essa política não atingiu a eficácia e a eficiência esperadas, considerando que houve um consumo grande de recursos empregados para sua execução. Termina afirmando que a “orientação pedagógica das atividades dos alunos é uma das formas de assegurar o bom uso da tecnologia. A capacitação do professor para o manuseio das novas mídias é condição primeira para a modernização dos processos de ensino” (SILVA, 2017, p. 97).

Já a pesquisa de Linhares e Ferreira (2012), nasce do interesse em identificar um perfil tecnológico docente do núcleo da cidade de Itabaiana, em Sergipe, no curso de formação para o PROUCA. Algumas questões que nortearam o estudo foram: "Quem são estes professores? Qual sua condição de incluído digital? Qual o seu domínio das TIC como mediador no processo de aprender e ensinar? Será que nas suas atividades diárias eles utilizam as TIC? Como eles usam as TIC em seu cotidiano?” (LINHARES; FERREIRA, 2012, p. 3)

Segundo as pesquisadoras, o perfil do professor é de quase um semianalfabetismo digital. Sobre as dificuldades encontradas pelos docentes, elas consideram ser ainda mais preocupantes, pois há desconhecimento das possibilidades cognitivas das TIC, além de desconhecimento do papel dessas tecnologias e de seus usos por seus alunos.

Precisamos ficar atentos com esse discurso que responsabiliza os professores pela “eficiência” e sucesso das políticas educacionais e consequentemente, do ensino. Isso acaba retirando dos governantes e das agências orientadoras a responsabilidade pela importação e adoção de modelos e experiências educacionais dicotômicas de outros países. O PROUCA é justamente um exemplo disso, um projeto que nasce no Estados Unidos e tem repercussão mundial, chegando em vários países, dentre entre eles o Brasil (PISCHETOLA, 2015).

O artigo de Pischetola (2015) apresentou uma pesquisa comparativa do projeto PROUCA em três países diferentes: Itália, Etiópia e Brasil. A pesquisa teve abordagem qualitativa, efetivada com observação participante, grupo focais com alunos e entrevistas com professores, coordenadores e gestores de escolas de ensino fundamental.

Um conceito central do estudo foi o de inclusão digital considerado, conforme pontua a autora, a partir de um ponto de vista mais amplo, relacionando-o com a realidade cultural. Dessa forma, a inclusão digital está "para além do acesso técnico e econômico às TIC, abordando-a como um meio de inclusão cidadã à cultura digital, mediante o desenvolvimento de habilidades de uso estratégico da tecnologia” (PISTECHOLA, 2015, p. 7). Compactuamos com a perspectiva de que a inclusão digital é vista de forma crítica e pensada também numa dimensão cultural, ao invés de ser reduzida ao acesso de aparelhos, máquinas, etc. cujo 
premissa se resume numa ideia que esses instrumentos são neutros podendo haver uma separação completa entre meios e fins (FEENBERG, 2003; 2015).

Nesse encaminhamento, a pesquisadora problematizou o conceito de inclusão digital com três dimensões a serem pesquisadas nos contextos educativos: a) o desenvolvimento de habilidades nos alunos; b) a motivação para aprender mediante o uso de tecnologia em sala de aula; e c) a adaptação dos professores a um novo contexto de trabalho. Os resultados desse estudo evidenciaram que, embora o professor reconheça a tecnologia como uma cultura, o modo que ele mais utiliza é como uma ferramenta.

Além disso, foi constatado que a inclusão digital depende da qualidade de acesso, no sentido de que é preciso saber empregar os recursos nas práticas docentes. Para a autora, "só dessa forma será dada ao professor a oportunidade de vivenciar situações dinâmicas que viabilizem uma verdadeira mudança na prática pedagógica, superando a ideia de que “tecnologia” equivale a "inovação” e "inclusão” (PISTECHOLA, 2015, p. 18).

Os trabalhos de Velloso (2011; 2013) e Soares e Valentini (2011), analisaram, de maneira geral, os desdobramentos da inserção dos laptops do PROUCA nas práticas pedagógicas. Essa motivação ocorre pelo fato de que a referência teórica do programa possui uma concepção de ensino e aprendizagem fundamentada na reformulação da relação do professor-aluno, com uma ideia de uma coconstrução de saberes (PISTECHOLA, 2015). Esta é uma concepção que se insere dentro das teorias construtivistas de aprendizagem em que o aluno possui um papel ativo na construção do conhecimento e o professor é considerado um facilitador, mediador, guia ou ainda como um orientador. Com essa premissa, Soares e Valentini (2011) buscaram identificar práticas de letramento digital por parte dos professores e alunos. Conseguiram com o estudo identificar três grandes categorias dessa prática: a) buscar e pesquisar na web, b) comunicar e c) publicar.

Já Velloso (2011; 2013) realizou pesquisas de cunho etnográfico na primeira escola do Rio de Janeiro que recebeu a implementação do PROUCA. Foram realizadas observações sistemáticas no cotidiano da escola, conversas informais, entrevistas, fotografias e levantamentos das matérias divulgadas pelo site oficial do programa. Isso foi realizado com o intuito de observar os impactos do programa na prática pedagógica e os processos de tradução e ressignificação envolvidos no ambiente escolar.

Os dados decorrentes desses estudos evidenciaram que os notebooks até proporcionaram outras interações nas salas de aulas como do aluno com o computador e entre eles. No entanto, a pesquisadora afirma que "o/a professor/a permanece no centro do processo, orientando o grupo sobre os sites a entrarem, sobre o que deveria ser pesquisado e as tarefas que deveriam ser cumpridas” (VELLOSO, 2013, p. 9). Outra questão que foi observada é que o computador pouco mudou a relação com os conteúdos.

Os computadores, conforme destaca a autora, são vistos, em algumas aulas, como um acessório e os professores possuem a visão de uma “aula perdida” em termos de conteúdos. Mesmo mudando para a lógica de um computador para cada aluno, ainda permanece impregnado um formato tradicional de ensino e aprendizagem, conforme destacado também por Oliveira (2011), mas com uma pesquisa em uma escola que possuía um laboratório de informática. 
O trabalho de Silva (2014), objetivou identificar e sistematizar o conhecimento científico acerca do PROUCA a partir de uma revisão de literatura no banco de dados da Coordenação de Aperfeiçoamento de Pessoal de Nível Superior (CAPES) e da BDTD entre o período de 2008 a 2013. Além disso, foram revisadas seis avaliações de processo contratadas pelos Poderes Executivo e Legislativo. A pesquisa encontrou um total de 37 dissertações de mestrado e 4 teses de doutorado. Segundo a autora, os trabalhos demonstram haver:

inadequação de infraestrutura nas escolas; suporte técnico e pedagógico insuficiente para atender as demandas; velocidade de acesso à internet inferior ao necessário para desenvolver atividades usando os laptops e, dependendo da localidade, inclusive, inexistência de conexão; problemas na organização estrutural dos cursos de capacitação ofertados; subutilização dos equipamentos e baixa frequência de uso nos contextos escolares; ausência de coordenação entre as três esferas de governo e de um planejamento específico para conduzir a sua execução (SILVA, 2014, p. 173).

Na tentativa de síntese, podemos destacar que os principais fatores analisados nas políticas do PROINFO e PROUCA se referem, primeiramente, à formação, em que há uma preocupação de formar os professores para fazer uso das tecnologias. Em segundo, encontram-se as análises das práticas pedagógicas e dos processos de ensino e aprendizagem que ocorrem a partir do uso dos equipamentos disponibilizados pelos programas. Já no que diz respeito a avaliação, existe um conjunto de pesquisas que buscam aferir a relevância, eficiência e eficácia ${ }^{8}$ do desempenho dos programas em confronto com os objetivos estabelecidos em uma tentativa de identificar tanto os problemas, limitações, quanto potencialidades e alternativas.

Com as análises, foi possível observar uma recorrência nos estudos sobre como consideram importante analisar o papel desempenhado pelos diferentes atores envolvidos numa iniciativa governamental, haja vista que buscam "ouvir” as múltiplas vozes envolvidas. Por último, mas não menos importante, podemos destacar que, independentemente do foco das pesquisas, um conceito central que emergiu é o de inclusão digital. No item a seguir, apresentaremos as pesquisas que analisaram as tecnologias nas políticas curriculares.

\subsubsection{Políticas curriculares e tecnologias}

O estudo em tela encontrou dois trabalhos que discutem a relação das políticas curriculares e as tecnologias. O primeiro é o artigo de Farias (2015) que buscou analisar a produção dos discursos que defendem uma política curricular para introdução e uso das TICs nos currículos, especificamente na região Ibero-Americana. Para tanto, foram analisados os documentos de dois organismos internacionais: Organização dos Estados Ibero-Americanos para a Educação, a Ciência e a Cultura (OEI) e Organização das Nações Unidas para a Educação, Ciência e Cultura (UNESCO). 
A pesquisa se fundamenta a partir de abordagem teórico-metodológica da Teoria do Discurso (TD) de Ernesto Laclau. Com isso, compreende a política como discurso em que existe representações em disputas que buscam se hegemonizar em determinado período. Farias (2015), nesse caso, buscou identificar e analisar as disputas de sentidos dos usos das TICs no âmbito da região Ibero-Americana.

Após as análises, a pesquisadora considera que existe um consenso: com o uso das TICs será possível superar e ultrapassar práticas de ensino tradicionais, uma concepção de escola tradicional. Mas, para que isso ocorra, destacam a figura do professor como protagonista. A respeito disso, há uma observação importante destacada por Farias (2015), de que há um discurso em que a superação das práticas tradicionais está fortemente vinculada a uma busca de melhoria de qualidade da educação e que isso passa também pela integração das tecnologias.

Destarte, a autora identificou que as tecnologias se configuram como uma questão inexorável para atingir e alcançar o que chamam de sociedade do conhecimento. Isso ocorre por alguns motivos:

seja pela necessidade de introdução das ferramentas tecnológicas nas escolas; seja na possibilidade de desenvolver novas habilidades na futura mão de obra; seja na expectativa de melhoria da qualidade da educação ou mesmo na intenção de uma maior aproximação dos jovens à escola a partir do seu uso (FARIAS, 2015, p. 3).

Por último, afirma que a dimensão que vem assumindo o papel das TICs na educação acaba por produzir um discurso hegemônico em defesa do seu uso nas políticas curriculares.

Em outro direcionamento, Amaral (2015), realizou uma pesquisa que refletiu sobre a articulação entre o papel das tecnologias digitais de informação e comunicação, as políticas públicas educacionais e a construção do currículo da educação profissional técnica de nível médio no Brasil. A pergunta que norteou a pesquisa era:

O que as Diretrizes Curriculares Nacionais Gerais da Educação Básica, do Ensino Médio e da Educação Profissional Técnica de Nível Médio referenciam sobre o uso ou integração das TDIC para subsidiar a construção dos Projetos Pedagógicos dos cursos Técnicos em Informática Integrados ao Ensino Médio? (AMARAL, 2015, p. 34).

A autora analisou três diretrizes: Diretrizes Curriculares Nacionais Gerais da Educação Básica, as Diretrizes Curriculares Nacionais do Ensino Médio, as Diretrizes Curriculares Nacionais da Educação Profissional Técnica de Nível Médio; e o Projeto Pedagógico do curso Técnico em Informática Integrado ao Ensino Médio de um Instituto Federal de São Paulo para, no final, realizar uma correlação entre todos estes documentos.

Como resultado da análise das Diretrizes Curriculares Nacionais Gerais da Educação Básica foram localizados quatro indicadores de TICs: 
O indicador Tecnologias como recurso didático-pedagógico e inserção à Cultura Digital se refere ao uso das tecnologias como recurso ao processo de ensino e aprendizagem e a inserção do professor à cultura digital. O indicador TDIC como elemento transversal ao currículo prevê que as tecnologias digitais da informação e comunicação são elementos transversais que devem perpassar pela base comum e parte diversificada do currículo. [...] O indicador TDIC como meio se refere, neste documento, ao uso das tecnologias digitais da informação e comunicação na mediatização das atividades educativas na educação a distância (AMARAL, 2015, p. 93).

A autora, fazendo uma análise mais ampla, em que contempla os diferentes documentos das políticas analisadas, identificou que eles fazem referência ao uso e integração das TDIC como recurso, ferramenta, dispositivo, instrumento, meio à prática educativa e construção do conhecimento. Destaca, ainda, que as tecnologias são mais do que apêndices, dispositivos periféricos no processo educativo e que precisam ser compreendidos como elemento estruturante do currículo.

Com as análises, compreendemos que os trabalhos que estudaram as tecnologias e as políticas curriculares demonstram a presença de forte concepção instrumentalista da tecnologia (FEENBERG, 2003; 2015) nos documentos analisados. Ou seja, acredita-se que a incorporação das tecnologias de maneira ferramental poderá engendrar, por si só, novas mudanças nos currículos e nos processos de ensino e aprendizagem.

\section{Apontamentos conclusivos para o campo}

Analisando as produções acadêmicas, no período de 1990 até 2019, publicadas em formato de artigo nos eventos da Associação Nacional de Pós-Graduação e Pesquisa em Educação (ANPED), e as dissertações e teses disponibilizadas na Biblioteca Digital Brasileira de Teses e Dissertações (BDTD), conseguimos mapear o campo das Políticas Curriculares, Políticas Educacionais e Tecnologias.

Os enunciados expressos nas pesquisas são imbricados com relações de poder e tecidos nas instituições que os difundem. Percebemos a força dos autores que atuam em instituições localizadas na Região Sudeste, concentrando quase metade da produção das pesquisas. No que concerne à perspectiva epistemológica dos pesquisadores, observamos que são as teorias críticas que aparecem, no cenário atual, como as produtoras de subjetividades e regimes de verdade no campo das políticas e tecnologias.

Identificamos algumas tendências, recorrências e lacunas na literatura que trazemos neste momento. A primeira recorrência diz respeito aos objetivos centrais das pesquisas. Podemos afirmar que há grande preocupação em analisar e avaliar o processo de implementação das políticas educacionais nos diferentes municípios do Brasil e, consequentemente, nos múltiplos cotidianos escolares. 
Diretamente relacionada com a primeira recorrência, estão os principais elementos analisados nos contextos de implementação das políticas. Entre os quais, há uma grande preocupação em analisar: a) as formações ofertadas pelos programas; b) as práticas pedagógicas e os processos de ensino e aprendizagem que ocorrem a partir do uso das tecnologias que foram incorporadas nos currículos; e c) a eficiência e eficácia do desempenho dos programas na busca de efetivar uma avaliação.

Os enunciados discursivos dos pesquisadores produzem efeitos de verdade, constatamos, assim, um número expressivo de trabalhos (re)afirmam que a incorporação das tecnologias superaria e transformaria as práticas de ensino e aprendizagem tradicionais, podendo levar a uma melhora da qualidade da educação. É uma perspectiva de que tecnologia equivale à "inovação", "progresso" e "eficiência”. Adicionado a isso, notamos que uma parte significativa dos trabalhos menciona a subutilização dos computadores e a sua baixa frequência de uso, configurando-se, muitas vezes, como um corpo estranho no cotidiano das escolas. E mesmo quando são utilizados, prevalece a configuração nos moldes do currículo tradicional. Em suma, demonstra-se os limites da aposta de uma concepção Instrumental das tecnologias que ainda está muito presente.

No que concerne às lacunas das produções acadêmicas, chama-nos a atenção a pouca preocupação dos pesquisadores em analisar os documentos das políticas. Certos estudos chegam a ter uma etapa da pesquisa caracterizada como documental. Em outras, essa análise não aparece em nenhum momento. Quando realizada, observamos que ela se dá de forma descritiva, com uma apresentação histórica das fases e etapas da política, assim como seus objetivos e premissas. Há escassez de problematização e de compreensão mais ampla do discurso presente nas políticas especialmente as relacionadas à concepção de tecnologia que está sendo contemplada. Destacamos, ainda, que nenhum estudo teve como objetivo central a análise dos documentos das políticas e não encontramos um que tivesse reconhecido um recorte temporal, isto é, uma análise com um período amplo que contemplasse mais de uma política.

Outra lacuna identificada na literatura é a pouca atenção dada às políticas curriculares. Para além das políticas educacionais específicas sobre tecnologias, como o PROINFO e o PROUCA, existem políticas curriculares em que há diretrizes relacionadas à incorporação das tecnologias nos currículos. Esse dado ficou mais evidente, principalmente, nas buscas realizadas no GT 12 de Currículo da ANPED, pois em 19 anos foram localizados somente dois trabalhos. Salientamos, na companhia de Foucault, que cada regime de verdade é composto, ao mesmo tempo, tanto por discursos acolhidos como verdadeiros quanto por discursos considerados falsos, isto é, as falas (não) sancionadas que podem delimitar o que é a verdade. Isto nos ajude, talvez, a compreender lacunas como esta que encontramos.

Diante deste estado do conhecimento, demonstramos, então, recorrências e lacunas nos três campos que dialogaram com a literatura, as quais sinalizaram o capital intelectual produzido e os regimes de verdade instituídos. Além de apontarem os limites epistemológicos que podem ser superados por pesquisas futuras. 


\section{Notas}

1. O recorte temporal começa no início da década de 1990 - quando nossos campos acadêmicos se consolidaram - até o ano de 2019.

2. A partir de 2013, as reuniões nacionais da Anped - que eram anuais - passaram a ocorrer bienalmente (de modo a intercalar, a cada ano, encontros nacionais e regionais da Associação).

3. Em relação as palavras-chave, é preciso esclarecer que elas não se restringem necessariamente às definidas pelos autores, pois em alguns artigos não foram localizadas. Observamos, então, expressões que esclarecem a centralidade dos textos analisados.

4. Utilizaremos o termo "trabalhos” para fazer referência ao conjunto de artigos, dissertações e teses.

5. Em 2007, o programa muda de nome e a sigla ganha um adjetivo, passando a chamar-se Programa Nacional de Tecnologia Educacional (Proinfo Integrado).

6. São textos políticos produzidos pela Organização dos Estados Ibero-americanos (OEI) e Organização das Nações Unidas para a Educação, a Ciência e a Cultura (UNESCO) (FARIAS, 2015).

7. Optamos por manter as nomenclaturas utilizadas pelos autores, apesar de elas não condizerem com a perspectiva que assumimos nesta pesquisa.

8. Os termos eficiência e eficácia são utilizados pelas próprias pesquisas que analisamos. Optamos por mantê-los, mesmo se discordássemos dessa perspectiva.

\section{Referências}

AMARAL, Maria Lucia Soares Do. As tecnologias digitais da informação e comunicação no currículo da educação profissional técnica de nível médio. 2015. Dissertação (Mestrado) - Pontifícia Universidade Católica de São Paulo, São Paulo, 2015.

CORREA E CASTRO, Marcia. Leituras do PROINFO integrado na rede pública de ensino do Estado do Rio de Janeiro. In: REUNIÃO ANUAL DA ASSOCIAÇÃO NACIONAL DE PÓS-GRADUAÇÃO E PESQUISA EM EDUCAÇÃO 2011, Natal. Anais [...]. Natal Disponível em: http://34reuniao.anped.org.br/images/trabalhos/GT16/GT16-1035 int.pdf.

FARIAS, Lívia Cardoso De. Currículo, qualidade e as tecnologias de informação e comunicação (TICS) no espaço Ibero-Americano. In: REUNIÃO ANUAL DA ASSOCIAÇÃ̃O NACIONAL DE PÓSGRADUAÇÃO E PESQUISA EM EDUCAÇÃO 2015, Florianópolis. Anais [...]. Florianópolis Disponível em: http://36reuniao.anped.org.br/pdfs_sessoes_especiais/se_05_norakrawcyk_gt05.pdf.

FARIAS, Maria da Salete Barboza De. Racionalidade capitalista e novas tecnologias na educação brasileira. 2006. Tese (Doutorado) - Universidade Federal de Pernambuco, Recife, 2006.

LIMA, Tania Maria Batista De. Políticas de formação docente e tecnologias digitais: o caso do Programa de Informatização das Escolas Públicas Brasileiras (PROINFO) nos Estados do Ceará e Bahia (19982004). 2006. Tese (Doutorado) - Universidade Federal do Ceará, Fortaleza, 2006.

LINHARES, Ronaldo Nunes; FERREIRA, Simone de Lucena. Reflexões sobre o perfil tecnológico dos professores do núcleo de Itabaiana/Sergipe no curso de formação para PROUCA. In: REUNIÃO ANUAL DA ASSOCIAÇÃO NACIONAL DE PÓS-GRADUAÇÃO E PESQUISA EM EDUCAÇÃO 2012, Porto de Galinhas. Anais [...]. Porto de Galinhas Disponível em: http://35reuniao.anped.org.br/images/stories/trabalhos/GT16 Trabalhos/GT16-1892_int.pdf.

MARTINS, Iris Laura Batista. Política pública e educação digital no ensino fundamental em Natal/RN: análise de eficácia da atuação dos objetivos do Proinfo Municipal. 2009. Dissertação (Mestrado) Universidade Federal do Rio Grande do Norte, Natal, 2009. 
NÓBREGA, Gabriela Carvalho Da. Dispositivos tecnológicos nas escolas como política educacional: uma análise a partir do Programa Aluno Conectado. 2015. Dissertação (Mestrado) - Universidade Federal de Pernambuco, Recife, 2015.

OLIVEIRA, Hérica Queiroz. Tecnologias de informação e comunicação na educação e Inclusão sociodigital: uma avaliação do programa de Informática na educação - PROINFO em Fortaleza. 2011. Dissertação (Mestrado) - Universidade Federal do Ceará, Fortaleza, 2011.

PISCHETOLA, Magda. Tecnologias em sala de aula: contribuições para uma pedagogia sustentável. In: REUNIÃO ANUAL DA ASSOCIAÇÃO NACIONAL DE PÓS-GRADUAÇÃO E PESQUISA EM EDUCAÇÃO 2015, Florianópolis. Anais [...]. Florianópolis

RICHITELI, Aurélio Alberto. Políticas Para a Inclusão Digital: Práticas E Possibilidades Na Escola Pública. 2017. Dissertação (Mestrado) - Universidade Federal Do Triângulo Mineiro, Uberaba, 2017.

RODRIGUES, Roberto Nunes. Avaliação de políticas públicas de educação: uma análise da eficácia do Programa Nacional de Tecnologia Educacional (Proinfo) no município de Gurupi-TO. 2019. Dissertação (Mestrado) - Universidade Federal do Tocantins, Palmas, 2019.

SANTOS, Marieunice Pereira Campos Dos. Mapeamento de pesquisas sobre políticas educacionais para o uso das TIC na educação básica. 2015. Dissertação (Mestrado) - Pontifícia Universidade Católica de Goiás, Goiânia, 2015.

SANTOS, Nilma Fernandes do Amaral. IDEB e tecnologias educacionais. In: REUNIÃO ANUAL DA ASSOCIAÇÃO NACIONAL DE PÓS-GRADUAÇÃO E PESQUISA EM EDUCAÇÃO 2013, Goiânia. Anais [...]. Goiânia Disponível http://36reuniao.anped.org.br/pdfs_trabalhos_aprovados/gt16_trabalhos_pdfs/gt16_2579_texto.pdf.

SARIAN, Maristela Cury. A injunção ao novo e a repetição do velho: um olhar discursivo ao programa um computador por aluno (PROUCA). 2012. Tese (Doutorado) - Universidade Estadual de Campinas, Campinas, 2012.

SILVA, Lívia Maria Ferreira Da. Políticas públicas de educação: avaliação de impacto do programa um computador por aluno (PROUCA). 2017. Dissertação (Mestrado) - Universidade Federal de Campina Grande, Campina Grande, 2017.

SILVA, Luana Rodrigues de Souza Da. Implementação do Programa Um Computador por Aluno: uma revisão da literatura. 2014. Dissertação (Mestrado) - Universidade Estadual de Campinas, Campinas, 2014.

SIQUEIRA, Romilson Martins. O Programa "Um Salto para o Futuro" e o discurso da formação continuada de professores. In: REUNIÃO ANUAL DA ASSOCIAÇÃO NACIONAL DE PÓS GRADUAÇÃO E PESQUISA EM EDUCAÇÃO 2001, Caxambu. Anais [...]. Caxambu Disponível em: http://24reuniao.anped.org.br/T0518408126923.DOC.

SOARES, Eliana Maria do Sacramento; VALENTINI, Carla Beatris. Práticas de letramento digital no contexto da inclusão de laptops educacionais. In: REUNIÃO ANUAL DA ASSOCIAÇÃO NACIONAL DE PÓSGRADUAÇÃO E PESQUISA EM EDUCAÇÃO 2011, Natal. Anais [...]. Natal Disponível em: http://34reuniao.anped.org.br/images/trabalhos/GT16/GT16-870 int.pdf.

SOSSAI, Fernando Cesar; GRIMM, Viviane; LOUREIRO, Carla Cristiane. Escritos sobre tecnologias e políticas educacionais no Brasil: uma análise dos trabalhos publicados pela Anped e RBPAE. RELATEC: Revista Latinoamericana de Tecnología Educativa, Extremadura, v. 15, n. 3, p. 39-54, 2016.

TELLO, C. G. Las epistemologías de la política educativa: vigilância y posicionamiento epistemológico del investigador en la política educativa. Práxis Educativa, [S. l.], v. 7, p. 53-68, 2012.

TOSTA, Sandra Pereira; OLIVEIRA, Maria Auxiliadora Monteiro. O computador não é uma lousa: as tecnologias de comunicação e informação e a prática docente. In: REUNIÃO ANUAL DA ASSOCIAÇÃO 
NACIONAL DE PÓS-GRADUAÇÃO E PESQUISA EM EDUCAÇÃO 2001, Caxambu. Anais [...]. Caxambu Disponível em: http://24reuniao.anped.org.br/T1653862827519.doc.

VELLOSO, Luciana. Conectando a rede: recontextualizações do projeto "Um computador por aluno" (UCA) em uma escola municipal do Rio de Janeiro. In: REUNIÃO ANUAL DA ASSOCIAÇÃO NACIONAL DE PÓS-GRADUAÇÃO E PESQUISA EM EDUCAÇÃO 2011, Natal. Anais [...]. Natal Disponível em: http://34reuniao.anped.org.br/images/trabalhos/GT12/GT12-479 int.pdf.

VELLOSO, Luciana. "Programa um computador por aluno" (PROUCA) em uma escola municipal do Rio de Janeiro: O que há de novo na rede? In: REUNIÃO ANUAL DA ASSOCIAÇÃO NACIONAL DE PÓSGRADUAÇÃO E PESQUISA EM EDUCAÇÃO 2013, Goiânia. Anais [...]. Goiânia Disponível em: http://36reuniao.anped.org.br/pdfs_trabalhos_aprovados/gt16_trabalhos_pdfs/gt16_2955_texto.pdf.

VIEIRA, Paula Michelle Teixeira. O PROINFO no entrecruzamento de seus diferentes discursos: um estudo bakitiniano. In: REUNIÃO ANUAL DA ASSOCIAÇÃO NACIONAL DE PÓS-GRADUAÇÃO E PESQUISA EM EDUCAÇÃO 2003, Poços de Calda. Anais [...]. Poços de Calda Disponível em: http://26reuniao.anped.org.br/trabalhos/paulamichelleteixeiravieira.rtf.

CASTELLS, Manuel. A Sociedade em Rede. São Paulo: Paz e Terra, 2000.

CORREA E CASTRO, Marcia. Leituras do PROINFO integrado na rede pública de ensino do Estado do Rio de Janeiro. In: REUNIÃO ANUAL DA ASSOCIAÇÃO NACIONAL DE PÓS-GRADUAÇÃO E PESQUISA EM EDUCAÇÃO 2011, Natal. Anais [...]. Natal Disponível em: http://34reuniao.anped.org.br/images/trabalhos/GT16/GT16-1035 int.pdf.

COUTO, Edvaldo Souza. O zumbido do híbrido: A filosofia ciborgue do corpo. In: ASSOCIAÇÃO NACIONAL DOS PROGRAMAS DE PÓS-GRADUAÇÃO EM COMUNICAÇÃO 2001, Brasília. Anais [...]. Brasília Disponível em: http://www.compos.org.br/data/biblioteca_1299.pdf.

FARIAS, Lívia Cardoso De. Currículo, qualidade e as tecnologias de informação e comunicação (TICS) no espaço Ibero-Americano. In: REUNIÃO ANUAL DA ASSOCIAÇÃ̃O NACIONAL DE PÓSGRADUAÇÃO E PESQUISA EM EDUCAÇÃO 2015, Florianópolis. Anais [...]. Florianópolis Disponível em: http://36reuniao.anped.org.br/pdfs_sessoes_especiais/se_05_norakrawcyk_gt05.pdf.

FARIAS, Maria da Salete Barboza De. Racionalidade capitalista e novas tecnologias na educação brasileira. 2006. Tese (Doutorado) - Universidade Federal de Pernambuco, Recife, 2006.

FEENBERG, Andrew. What is Philosophy of Technology? In: 2003, Tokyo. Anais [...]. Tokyo: Komaba, 2003.

FEENBERG, Andrew. Tecnologia, Modernidade e Democracia. Portugal: Inovatec, 2015.

FONSECA, Tania Mara Galli; COSTA, Luiz Artur; KIRST, Patrícia Gomes. Ritornelos para o pesquisar no contexto das tecnologias virtuais do sensível. Informática na educação: teoria e prática, v. 11, n. 1, p. 38-46, 2008.

FOUCAULT, Michel. A Ordem do discurso. São Paulo: Edições Loyola, 1971.

FOUCAULT, Michel. Microfísica do Poder. Rio de Janeiro: Graal, 1979.

FOUCAULT, Michel. A Arqueologia do saber. 7. ed. Rio de Janeiro: Forense universitária, 1986.

LIMA, Tania Maria Batista De. Políticas de formação docente e tecnologias digitais: o caso do Programa de Informatização das Escolas Públicas Brasileiras (PROINFO) nos Estados do Ceará e Bahia (19982004). 2006. Tese (Doutorado) - Universidade Federal do Ceará, Fortaleza, 2006.

LINHARES, Ronaldo Nunes; FERREIRA, Simone de Lucena. Reflexões sobre o perfil tecnológico dos professores do núcleo de Itabaiana/Sergipe no curso de formação para PROUCA. In: REUNIÃO ANUAL DA ASSOCIAÇÃO NACIONAL DE PÓS-GRADUAÇÃO E PESQUISA EM EDUCAÇÃO 2012, Porto de Galinhas. Anais [...]. Porto de Galinhas Disponível em: http://35reuniao.anped.org.br/images/stories/trabalhos/GT16 Trabalhos/GT16-1892_int.pdf. 
LOPES, Alice Casimiro; MACEDO, Elizabeth. Teorias de currículo. 1. ed. São Paulo: Cortez, 2011.

MARTINS, Iris Laura Batista. Política pública e educação digital no ensino fundamental em Natal/RN: análise de eficácia da atuação dos objetivos do Proinfo Municipal. 2009. Dissertação (Mestrado) Universidade Federal do Rio Grande do Norte, Natal, 2009.

NÓBREGA, Gabriela Carvalho Da. Dispositivos tecnológicos nas escolas como política educacional: uma análise a partir do Programa Aluno Conectado. 2015. Dissertação (Mestrado) - Universidade Federal de Pernambuco, Recife, 2015.

OLIVEIRA, Hérica Queiroz. Tecnologias de informação e comunicação na educação e Inclusão sociodigital: uma avaliação do programa de Informática na educação - PROINFO em Fortaleza. 2011. Dissertação (Mestrado) - Universidade Federal do Ceará, Fortaleza, 2011.

PISCHETOLA, Magda. Tecnologias em sala de aula: contribuições para uma pedagogia sustentável. In: REUNIÃO ANUAL DA ASSOCIAÇÃO NACIONAL DE PÓS-GRADUAÇÃO E PESQUISA EM EDUCAÇÃO 2015, Florianópolis. Anais [...]. Florianópolis

RICHITELI, Aurélio Alberto. Políticas Para a Inclusão Digital: Práticas E Possibilidades Na Escola Pública. 2017. Dissertação (Mestrado) - Universidade Federal Do Triângulo Mineiro, Uberaba, 2017.

RODRIGUES, Roberto Nunes. Avaliação de políticas públicas de educação: uma análise da eficácia do Programa Nacional de Tecnologia Educacional (Proinfo) no município de Gurupi-TO. 2019. Dissertação (Mestrado) - Universidade Federal do Tocantins, Palmas, 2019.

ROMANOWSKI, J. P.; ENS, R. T. As pesquisas denominadas do tipo “estado da arte” em educação. Diálogo Educacional, v. 6, n. 19, p. 37-50, set./dez., 2006.

ROMANOWSKI, Joana Paulin. As licenciaturas no Brasil: um balanço das teses e dissertações dos anos 90. Tese (Doutorado) - Faculdade de Educação da Universidade de São Paulo, São Paulo, 2002.

SANTOS, Marieunice Pereira Campos Dos. Mapeamento de pesquisas sobre políticas educacionais para o uso das TIC na educação básica. 2015. Dissertação (Mestrado) - Pontifícia Universidade Católica de Goiás, Goiânia, 2015.

SANTOS, Nilma Fernandes do Amaral. IDEB e tecnologias educacionais. In: REUNIÃO ANUAL DA ASSOCIAÇÃO NACIONAL DE PÓS-GRADUAÇÃO E PESQUISA EM EDUCAÇÃO 2013, Goiânia. Anais [...]. Goiânia http://36reuniao.anped.org.br/pdfs_trabalhos_aprovados/gt16_trabalhos_pdfs/gt16_2579_texto.pdf.

SARIAN, Maristela Cury. A injunção ao novo e a repetição do velho: um olhar discursivo ao programa um computador por aluno (PROUCA). 2012. Tese (Doutorado) - Universidade Estadual de Campinas, Campinas, 2012.

SEIXAS, Luciana Velloso da Silva. Conectando a rede: recontextualizações do projeto "Um computador por aluno” (UCA) em uma escola municipal do Rio de Janeiro. In: REUNIÃO ANUAL DA ASSOCIAÇÃO NACIONAL DE PÓS-GRADUAÇÃO E PESQUISA EM EDUCAÇÃO 2011, Natal. Anais [...]. Natal Disponível em: http://34reuniao.anped.org.br/images/trabalhos/GT12/GT12-479 int.pdf.

SEIXAS, Luciana Velloso da Silva. "Programa um computador por aluno" (PROUCA) em uma escola municipal do Rio de Janeiro: O que há de novo na rede? In: REUNIÃO ANUAL DA ASSOCIAÇÃO NACIONAL DE PÓS-GRADUAÇÃO E PESQUISA EM EDUCAÇÃO 2013, Goiânia. Anais [...]. Goiânia Disponível

em: http://36reuniao.anped.org.br/pdfs_trabalhos_aprovados/gt16_trabalhos_pdfs/gt16_2955_texto.pdf.

SILVA, Lívia Maria Ferreira Da. Políticas públicas de educação: avaliação de impacto do programa um computador por aluno (PROUCA). 2017. Dissertação (Mestrado) - Universidade Federal de Campina Grande, Campina Grande, 2017. 
SILVA, Luana Rodrigues de Souza Da. Implementação do Programa Um Computador por Aluno: uma revisão da literatura. 2014. Dissertação (Mestrado) - Universidade Estadual de Campinas, Campinas, 2014.

SIQUEIRA, Romilson Martins. O Programa "Um Salto para o Futuro" e o discurso da formação continuada de professores. In: REUNIÃO ANUAL DA ASSOCIAÇÃO NACIONAL DE PÓS GRADUAÇÃO E PESQUISA EM EDUCAÇÃO 2001, Caxambu. Anais [...]. Caxambu Disponível em: http://24reuniao.anped.org.br/T0518408126923.DOC.

SOARES, Eliana Maria do Sacramento; VALENTINI, Carla Beatris. Práticas de letramento digital no contexto da inclusão de laptops educacionais. In: REUNIÃO ANUAL DA ASSOCIAÇÃO NACIONAL DE PÓSGRADUAÇÃO E PESQUISA EM EDUCAÇÃO 2011, Natal. Anais [...]. Natal Disponível em: http://34reuniao.anped.org.br/images/trabalhos/GT16/GT16-870 int.pdf.

SOSSAI, Fernando Cesar; GRIMM, Viviane; LOUREIRO, Carla Cristiane. Escritos sobre tecnologias e políticas educacionais no Brasil: uma análise dos trabalhos publicados pela Anped e RBPAE. RELATEC: Revista Latinoamericana de Tecnología Educativa, Extremadura, v. 15, n. 3, p. 39-54, 2016.

TOSTA, Sandra Pereira; OLIVEIRA, Maria Auxiliadora Monteiro. O computador não é uma lousa: as tecnologias de comunicação e informação e a prática docente. In: REUNIÃO ANUAL DA ASSOCIAÇÃO NACIONAL DE PÓS-GRADUAÇÃO E PESQUISA EM EDUCAÇÃO 2001, Caxambu. Anais [...]. Caxambu Disponível em: http://24reuniao.anped.org.br/T1653862827519.doc.

VIEIRA, Paula Michelle Teixeira. O PROINFO no entrecruzamento de seus diferentes discursos: um estudo bakitiniano. In: REUNIÃO ANUAL DA ASSOCIAÇÃO NACIONAL DE PÓS-GRADUAÇÃO E PESQUISA EM EDUCAÇÃo 2003, Poços de Calda. Anais [...]. Poços de Calda Disponível em: http://26reuniao.anped.org.br/trabalhos/paulamichelleteixeiravieira.rtf.

\section{Correspondência}

Hugo Souza Garcia Ramos: Pedagogo, Mestre em Psicologia Institucional e Doutorando em Educação pela Universidade Federal do Espírito Santo - UFES. Bolsista CAPES.

Orcid: 0000-0002-8341-9784

E-mail: hugo-sgramos@hotmail.com

Geide Rosa Coelho: Graduado em Física Licenciatura pela Universidade Federal de Minas Gerais (2001), Mestre em Educação pela Universidade Federal de Minas Gerais (2007) e Doutor em Educação pela Universidade Federal de Minas Gerais (2011). Atualmente é professor da área de ensino de Física no Centro de Educação da Universidade Federal do Espírito Santo (2010) atuando no curso presencial e na modalidade a distância, e professor dos Programas de Pós-Graduação em Educação (PPGE) e Ensino de Física (PPGEnFis) da UFES.

Orcid: 0000-0001-5358-9742

E-mail: geidecoelho@gmail.com 
Texto publicado em Currículo sem Fronteiras com autorização dos autores. 